\title{
Non-classical congenital adrenal hyperplasia presenting as primary amenorrhoea with virilization
}

\section{Beeresh CS*, Divyasree Doopadapalli, Amita Ray, Krishna Lingegowda}

Department of Obstetrics \& Gynaecology, PES medical college, Kuppam, Chittor, Andhra Pradesh, India

Received: 28 July 2015

Accepted: 14 August 2015

\author{
*Correspondence: \\ Dr. Beeresh CS, \\ E-mail: beeresh.25@gmail.com
}

Copyright: (C) the author(s), publisher and licensee Medip Academy. This is an open-access article distributed under the terms of the Creative Commons Attribution Non-Commercial License, which permits unrestricted non-commercial use, distribution, and reproduction in any medium, provided the original work is properly cited.

\begin{abstract}
Primary amenorrhea presents a diagnostic challenge even to the most experienced clinicians. The number, variety and the complexity of disorder that must be considered can seem daunting and in many instances include unfamiliar organ system. One such disorder is congenital adrenal hyperplasia $(\mathrm{CAH})$. Here, we present a case of Non-classical congenital adrenal hyperplasia in a 16 year old female who presented to us with primary amenorrhea with virilization. This is an interesting case because of its unusual presentation, difficulty in diagnosis and complexity involved in treatment.
\end{abstract}

Keywords: Non classical congenital adrenal hyperplasia, Primary amenorrhea, Virilization

\section{INTRODUCTION}

Congenital adrenal hyperplasia $(\mathrm{CAH})$ is a disorder of the adrenal cortex characterized by cortisol deficiency, with or without aldosterone deficiency, and androgen excess. $\mathrm{CAH}$ shows a range of severity. The clinical phenotype is typically classified as classic, the severe form, or nonclassic, the mild or late-onset form. Classic CAH is sub classified as salt-losing or non-salt-losing (simple virilising), reflecting the degree of aldosterone deficiency. Data from close to 6.5 million new-born screenings worldwide indicate that classical $\mathrm{CAH}$ occurs in $1: 13,000$ to $1: 15,000$ live births. ${ }^{1}$ Non-classical also called as late onset congenital adrenal hyperplasia (LCAD) is more common.

We present a case of Non-classical congenital adrenal hyperplasia in a 16 year old female who presented to us with primary amenorrhea with virilization. This is an interesting case because of its unusual presentation, difficulty in diagnosis and complexity involved in treatment.

\section{CASE REPORT}

A 16 year old, reared as female since birth presented to gynaecology OPD with complaints of delayed menarche and excessive hair growth all over the body since one year. At birth her phenotypical appearance were that of a female and was reared as female since then her other developmental mile stones were appropriate for age. She was the first sibling of her family and had a younger sister of 14 years age. Her mother attained menarche at the age of 13 years and her younger sister at 12 years, both have regular cycles and had no symptoms suggestive of virilization. There was no history of deepening of voice, temporal balding or apparent change in body habits. No history of any drug intake that could stimulate excessive hair growth.

On clinical examination, she was moderately built and nourished. Height $150 \mathrm{cms}$, weight $45 \mathrm{kgs}$ and BMI of 20. Excessive hair growth were noted over upper lip (Figure 1), chin, side burns (Figure 2), upper arm, thighs and pubic region. Distribution and extent of hirsuitism 
assessed by modified Ferriman-Gallway score was 9, suggestive of moderate hirsuitism.

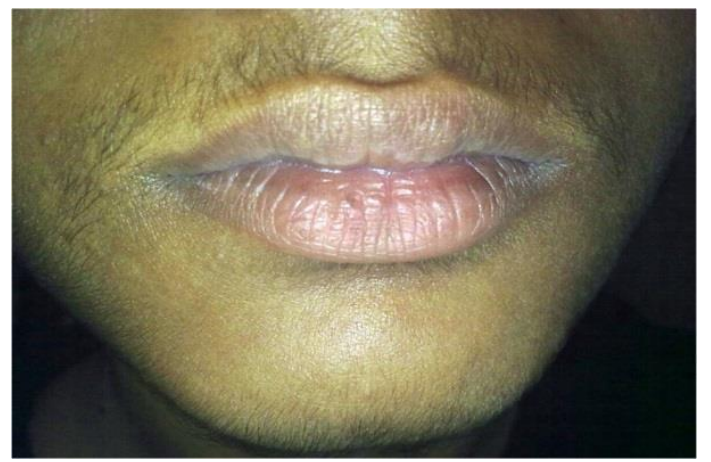

Figure 1: Excessive hair growth over upper lip and chin.

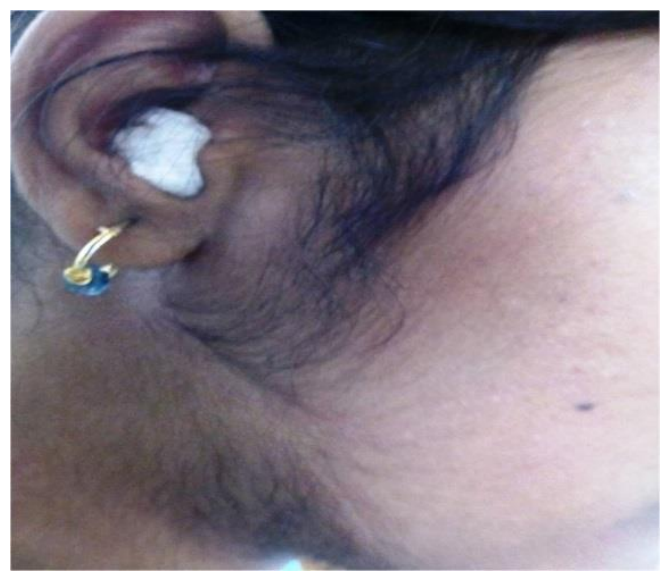

Figure 2: Excessive hair growth over side burns.

Bilateral breast budding present with tanner's stage 2 (Fig. 3). However there was no evidence of increased muscle mass, acathosis nigricans, skin striae, bruising or abdominal lump. Genital examination revealed clitoromegally (Fig. 4) with clitoral index of $40 \mathrm{~mm}$. Labia majora and minora appropriate for age, hymen intact, urethral opening was at the base of clitoris. Knob like structure was felt through per rectal examination which probably was uterus. There was no palpable inguinal mass.

With this history and clinical findings, following differential diagnosis were arrived and evaluated accordingly.

1. Androgen producing tumor.

2. Non-classical congenital adrenal hyperplasia.

3. Incomplete Androgen sensitivity syndrome.

4. Early onset PCOS

Ultrasonography showed uterus and bilateral ovaries normal in size shape and ecopattern. Endometrial thickness was $5 \mathrm{~mm}$. There was no detectable ovarian or adrenal mass. Total, bioavailable and free testosterones were elevated as expected and measured $97.80 \mathrm{ng} / \mathrm{dl}$,
$40.59 \mathrm{ng} / \mathrm{dl}$ and $1.73 \mathrm{ng} / \mathrm{dl}$ respectively. DHEAS is a type of androgen produced exclusively from adrenal and the level were not elevated $(268.70 \mathrm{mcg} / \mathrm{dl})$, this ruled out adrenal tumours. Normal levels of S. estradiol (63.58 pg. $/ \mathrm{ml})$ and FSH $(7.98 \mathrm{mIU} / \mathrm{ml})$ confirmed the adequate functioning of hypothalamic pituitary ovarian axis.

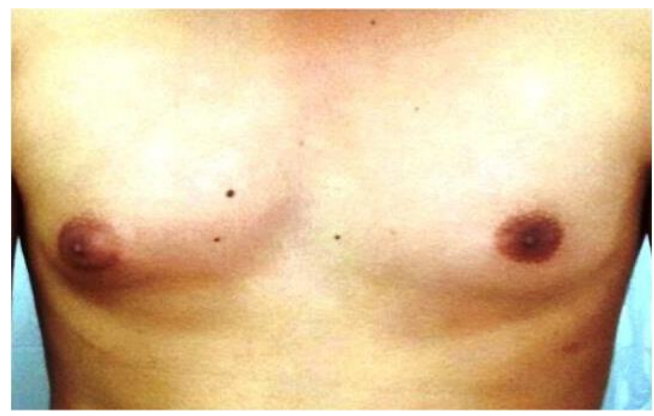

Figure 3: Breast development Tanner stage 2.

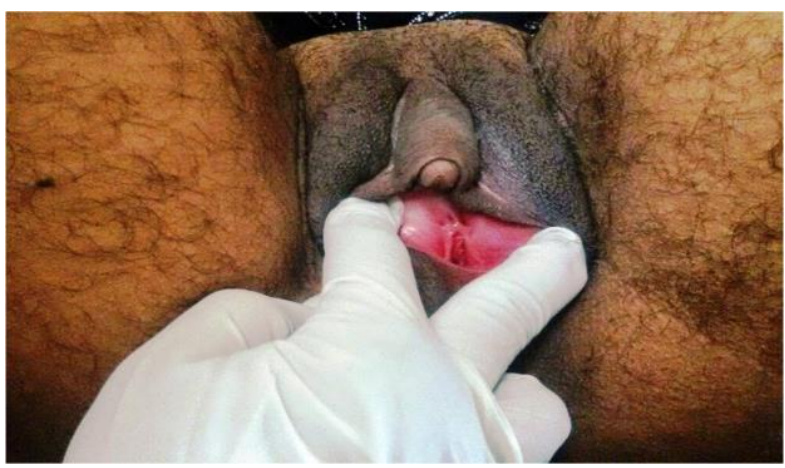

Figure 4: Clitoromegally.

Presence of mullerian derived structures (uterus) with presence of functional female gonad (normal S. Estradiol) ruled out incomplete androgen sensitivity syndrome. $17 \alpha$ hyroxyprogestone, an intermediate product in the biosynthesis of cortisol measured $560 \mathrm{ng} / \mathrm{dl}$ and was marginally elevated raising the suspicion of late onset congenital adrenal hyperplasia which was confirmed later by performing an ACTH stimulation test, obtaining blood sample before and $60 \mathrm{~min}$ after administration of synthetic ACTH $0.25 \mathrm{mg}$ IM, concentration of 17-OHP concentration above $1500 \mathrm{ng} / \mathrm{dl}$ confirms the diagnosis of $\mathrm{CAH}$ and in our case measured $1750 \mathrm{ng} / \mathrm{dl}$.

Patient and her parents were counselled regarding the diagnosis and were started on anti-androgenic oral contraceptive pills containing $35 \mu \mathrm{g}$ of etinyl estradiol and $2 \mu \mathrm{g}$ of cyproterene acetate since delayed menarche was one of their main concern. Patient attained her menarche on withdrawal with OCP. Her delayed menarche could possibly be explained due to chronic anovulation relating to excess production of adrenal androgen and progesterone (17-OHP). Symptomatic non-classical CAH also require treatment with glucocorticoids. Hydrocortisone remains the main treatment of choice and was started with $10 \mathrm{mg}$ per day. After 6 months of 
treatment with OCP and glucocorticoid, her hirsuitism significantly reduced and cycles were regular (Fig. 5).

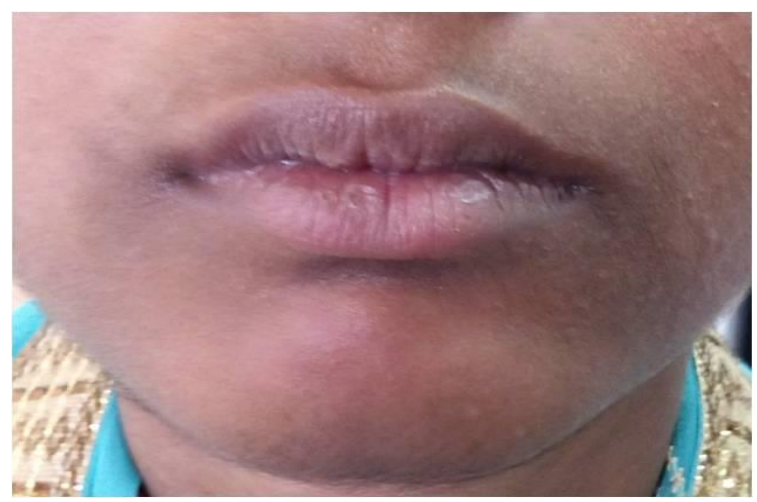

Figure 5: Resolution of hirsuitism after treatment.

\section{DISCUSSION}

$(\mathrm{CAH})$ is a family of autosomal recessive disorders of cortisol biosynthesis. The pathophysiology relates primarily to decreased cortisol production, which stimulates a compensatory increase in ACTH, causing increased level of steroid hormone proximal to the enzyme block seeking alternative metabolic pathway, resulting in increased androgen.

More than $90 \%$ are caused due to deficiency of 21 hydroxylase. Deficiencies of $11 \beta$-Hydroxylase and $3 \beta$ Hydroxysteroid dehydrogenase are less common. ${ }^{2}$ Depending on the time of onset, quantity available and duration of exposure of androgen, CAH can have a varied manifestation ranging from serious salt wasting variety with ambiguous genitalia at birth to simple virilization in adult. Salt-losing CAH accounts for $67 \%$ of the cases reported and non-salt-losing $\mathrm{CAH}$ for $33 \%$.

Congenital adrenal hyperplasia can affect both boys and girl's equally. CAH is one of the most frequent cause of sexual ambiguity and the most common endocrine cause of neonatal death. The most severe "salt wasting" variety is characterized by severe deficiency of cortisol and aldosterone, resulting in salt wasting and dehydration, in addition to virilization. In the less severe "simple virilization" form of the disorder, elevated level of ACTH are able to drive sufficient glucocorticoid and mineralocorticoid production to prevent circulatory collapse, but excess androgen produced in utero result in masculinization of the external genitalia. The third and the least severe "non-classical" form generally does not become apparent until adolescence or early childhood, when abnormally high level of androgen cause hirsuitism and precocious puberty. ${ }^{3}$ In our case patient presented with primary amenorrhea and hirsuitism which was unusual and probably was due to high level of circulating androgens having negative feedback effect on HPO axis inhibiting ovulation.
ACTH stimulation test constitutes the gold standard test for obtaining an accurate diagnosis of LCAH. After measuring the serum $17-\mathrm{OH} \mathrm{P}$, a single dose $(0.25 \mathrm{mg})$ of $\mathrm{ACTH}$ injection is performed. Concentration of 17-OHP concentration above $1500 \mathrm{ng} / \mathrm{dl}$ confirms the diagnosis of CAH. $^{4}$

Treatment for $\mathrm{CAH}$ is aimed at providing sufficient amount of glucocorticoid, to reduce excessive ACTH. Goal of treatment is to promote normal growth and development by providing sufficient hormone to minimize adrenal sex steroids production while minimizing the consequences of glucocorticoid excess. This can be achieved by treatment with hydrocortisone in the dose of $12-18 \mathrm{mg} / \mathrm{m} 2 / \mathrm{day}^{5}$, in this case were treated with $10 \mathrm{mg} /$ day.

\section{CONCLUSION}

This case emphasizes the importance of making the differential diagnosis of primary amenorrhea - hirsuitism and applying dynamic diagnostic tests with interdisciplinary follow-up in patients with hormonal diseases.

Funding: No funding sources

Conflict of interest: None declared

Ethical approval: Not required

\section{REFERENCES}

1. Pang SY, Wallace MA, Hofman L, et al. Worldwide experience in newborn screening for classical congenital adrenal hyperplasia due to 21-hydroxylase deficiency. Pediatrics 1988;81:866-74.

2. Genetic Steroid Disorders. New MI, Lekarev O, Parsa A, Yuen T, O’Malley B, Hammer G eds. 2013. Elsevier, San Diego, CA.

3. New M, Lekarev O, Lin-Su K, et al. Congenital Adrenal Hyperplasia. [Updated 2013 Oct 28]. In: De Groot LJ, Beck-Peccoz P, Chrousos G, et al., editors. Endotext [Internet]. South Dartmouth (MA): MDText.com, Inc.; 2000-. Available from: http://www.ncbi.nlm.nih.gov/books/NBK278953/

4. Aziz R, Rafi A, Smith BR, Bradley EL Jr, Zacur HA. On the origin of the elevated 17-hydroxyprogesterone levels after adrenal stimulation in hyperandrogenism. J Clin Endocrinol Metab 1990;70: 431-36.

5. Hindmarsh PC. Management of the child with congenital adrenal hyperplasia. Best Pract Res Clin Endocrinol Metab. 2009;23(2):193-208.

Cite this article as: Beeresh CS, Doopadapalli D, Ray A, Lingegowda K. Non-classical congenital adrenal hyperplasia presenting as primary amenorrhoea with virilization. Int J Reprod Contracept Obstet Gynecol 2015;4:1627-9. 